\title{
Lealdade e oportunismo nas cooperativas: desafios e mudanças na gestão
}

\author{
Flávio José Simioni ${ }^{1}$ \\ Elisabete Stradiotto Siqueira ${ }^{2}$ \\ Erlaine Binotto ${ }^{3}$ \\ Eduardo Eugênio Spers ${ }^{4}$ \\ Zilda Aparecida Soares de Araújo ${ }^{5}$
}

Resumo: O objetivo deste estudo é analisar como dirigentes e cooperados percebem os fatores que contribuem na construção de relações de lealdade com a cooperativa. Trata-se de uma pesquisa exploratória, com tipologia seccional. O meio de investigação utilizado foi pesquisa de campo por meio de um questionário aplicado a 12 dirigentes e 25 associados de cooperativas. A definição constitutiva que orientou a seleção das categorias de análise foi baseada em Oliver (1999). O estudo demonstrou que a deslealdade e o oportunismo estão presentes tanto nos dirigentes quanto nos cooperados, visto que a lealdade está condicionada à manutenção do status quo de cada um, relegando os valores cooperativistas de igualdade, coletividade e solidariedade a um segundo plano. Isso não é decorrente unicamente de um desvio comportamental dos associados, mas também é fruto das demandas que o ambiente institucional provoca nas organizações cooperativas que não conseguem responder adequadamente a tal contexto.

Palavras-chaves: cooperativa, lealdade, associado, oportunismo, economia institucional.

${ }^{1}$ Professor Adjunto da Universidade Federal de Goiás, Campus Jataí (UFG-CAJ). E-mail: fjsimioni@hotmail.com

${ }^{2}$ Professora Adjunta da Universidade Federal do Semi-Árido (UFERSA). E-mail: betebop@uol.com.br

${ }^{3}$ Professora Adjunta da Universidade Federal da Grande Dourados (UFGD). E-mail: e-binotto@uol.com.br

${ }^{4}$ Professor da Escola Superior de Propaganda e Marketing, Núcleo de Ensino em Gestão Internacional e da Escola Superior de Agricultura Luiz de Queiróz (Esalq), USP. Email: eespers@esalq.usp.br

${ }^{5}$ Professora da Faculdade de Ciências Administrativas e Contábeis Santa Lúcia. E-mail: zilda_araujo@terra.com.br 


\begin{abstract}
This paper aims to analyze how factors that contribute for loyalty relations in a cooperative are felt by managers and associates. Oliver (1999) was used as theoretical reference, and a questionnaire was applied to 12 managers and 25 associates. The study showed that disloyalty and opportunism are present both in managers and associates, considering that loyalty is linked to keep status quo of each one, relegating cooperativist values, such as equality, collectivity and solidarity. This is not a result attributed exclusively to associates' behavior, but also a consequence of demands that the institutional environment cause in cooperative organizations, which is unable to answer adequately to these context.
\end{abstract}

Key-words: cooperative, loyalty, associate, opportunism, institutional economy.

Classificação JEL: L14, Q13.

\title{
1. Introdução
}

As cooperativas agrícolas passaram, e estão passando, por adequações em suas posturas diante da realidade de mudanças constantes do mercado competitivo, uma vez que foram criadas e cresceram no período em que predominava a agricultura tradicional. Para fazer frente à nova realidade, elas buscaram se profissionalizar no que se refere à administração e às relações com os seus associados e se adaptar às regras do mercado, obtendo maior credibilidade. A cooperativa é vista hoje como uma ferramenta de desenvolvimento do setor, dando condições para o seu cooperado progredir com base em informações e orientações.

No Brasil, as cooperativas apresentam-se em diferentes situações: algumas em situação econômica privilegiada; outras ainda buscando formas de sobrevivência e adequação à realidade e, as demais, impossibilitadas de operar por causa de dificuldades financeiras e em processo de autoliquidação. Pode-se afirmar que algumas das causas estão relacionadas à falta de capacidade de adequação às mudanças, às novas tecnologias, falta de lealdade e fidelidade à organização, à instabilidade econômica das últimas décadas e aos decorrentes planos econômicos que se fizeram presentes por um longo período na economia brasileira.

Para Knutson (1966), a cooperativa agindo num mercado competitivo pode exercer influência sobre os preços, resultados e dimensões de competência comparável à de outras empresas. As características da cooperativa tradicional são as de uma organização defensiva, cuja função primária é manter outros competidores num mercado mais honesto.

Isso tem levado as cooperativas a investirem mais em capital físico que intelectual; a atenderem às necessidades de diferentes membros no que se refere a tamanho, à qualificação e a compromisso; a requererem o recebimento de todo o produto e a oferecerem uma ampla variedade de serviços, devido a sua preocupação social (COOK, 1995). 
Envolto no contexto cooperativo surgem problemas relacionados com posturas oportunísticas, caracterizando deslealdade de uma das partes, seja associado ou dirigente. Lealdade no ambiente cooperativo representa o cumprimento de um compromisso ético e moral para com os demais envolvidos.

Os princípios estabelecidos pela filosofia cooperativista são únicos em todo o mundo e entre as principais características desse modelo de gestão destaca-se o fato de que são controladas pelos seus próprios membros. Aqui se estabelece o primeiro desafio do modelo de gestão, que consiste em tentar chegar a um consenso (IRION, 1997).

Tais especificidades permitiriam supor que as cooperativas ocupam posição diferenciada no mercado, considerando que seus valores já deveriam incorporar uma postura ética mais elaborada, uma vez que existem como preceitos fundamentais.

Todas essas características que, supostamente, proporcionam às estruturas cooperativistas a harmonização democrática e transparente, não impedem os conflitos e jogos de interesses internos. Prova disso são as notícias de jornais sobre cooperativas que relatam casos de lideranças afastadas por fraudes ou, simplesmente, que fecharam suas portas por incapacidade administrativa de gerir o seu negócio.

Normalmente, não são estabelecidos contratos entre cooperativa e associados que garantam a entrega da produção. Há, sim, um contrato implícito pelo fato do cooperado fazer parte da organização e ser responsável pelo seu desenvolvimento e sustentabilidade, pois a rentabilidade possui ligação direta com a lealdade, sendo o melhor indicador de uma relação em longo prazo. Assim, a base que sustenta as relações de lealdade apóia-se em posturas éticas de ambas as partes, já que as punições são formas complexas de penalizar os que descumprirem os compromissos.

Machado Filho et al. (2004) afirmam que a sobrevivência do cooperativismo em um mundo cada vez mais dinâmico está ligada a sua profissionalização, à transparência e à praticidade. Para Morgan e Hunt (1994), a base para a construção e sustentação de um relacionamento de sucesso é o comprometimento e a confiança entre as partes envolvidas.

As cooperativas, assim como empresas privadas, atuam em um mercado competitivo. Se para as primeiras a prioridade de satisfação é de seu associado, para a segunda se refere aos clientes. Enquanto organizações, ambas têm investido esforços no sentido de manterem relacionamentos de lealdade mais duradouros com esses públicos.

No caso das cooperativas, elas disputam a lealdade de seus associados tanto com outras cooperativas como com as empresas privadas, devendo oferecer elementos que proporcionem satisfação, confiança e valores, que se constituem em condutores à lealdade. 
Contudo, a atuação das cooperativas não está limitada ao seu ambiente interno. Ela faz parte de um ambiente institucional que gera demandas e necessidades de adaptação, uma vez que interfere no comportamento dos agentes. Nesse sentido, a decisão dos cooperados em manter ou não a sua lealdade diante de situações em que sua condição individual se coloque em posição de risco traz, para a relação com a cooperativa, custos adicionais.

Dalmoro, Klein, Wittmann e Batistella (2008) sugerem que as redes sociais podem ter um custo de transação menor, visto que estão envolvidas por uma moral convencionada, capazes de gerar maior confiança nas relações econômicas. Os autores concluem que ainda que se reconheça nas cooperativas sua possibilidade de construção do capital social e, portanto, com custos transacionais menores, alguns elementos inibem seu desenvolvimento como, por exemplo, a centralização no comando.

Portanto, a estrutura de cooperação pode estabelecer relações entre custos de reputação e lealdade. Para orientar a análise da dimensão da lealdade no contexto cooperativista o artigo estabelece uma relação com os conceitos da economia dos custos de transação.

Diante desse quadro, o objetivo deste estudo foi analisar como dirigentes e cooperados percebem os fatores que contribuem na construção de relações de lealdade com a cooperativa.

\section{Referencial teórico}

\subsection{Cooperativismo}

A origem histórica do conceito de cooperativismo é atribuída à experiência de operários do bairro de Rochdale, em Manchester, na Inglaterra, que vivia o auge da Revolução Industrial. Inspirados nas idéias de Charles Fourier e Robert Owen (representantes do socialismo utópico, ou socialismo romântico) de uma sociedade ideal sem conflitos ou desigualdades, um grupo de 28 tecelões criou, em 1844, a Sociedade dos Probos Pioneiros de Rochdale, distrito de Manchester, formada a partir de um fundo constituído pela economia mensal de cada participante. Buscavam, naquele momento, uma alternativa econômica que lhes permitissem sobreviver naquela nova realidade, criando uma cooperativa de consumo, a fim de evitarem as especulações dos intermediários. A constituição do Armazém de Rochdale começou a mudar os padrões econômicos da época, dando origem ao que se conhece como movimento cooperativista (LEZAMIZ, 1993).

Amaral (2001) toma como marco inicial das cooperativas no Brasil a fundação da Colônia Teresa Cristina, em 1847, nos sertões do estado do Paraná, pelo médico francês Jean Maurice Faivre. Mas, tal iniciativa não durou muito tempo, devido à falta de ambiência política e econômica favorável, configurada pelo 
regime trabalhista da escravatura, em que a economia era centrada nas grandes propriedades que, dada sua auto-suficiência e o comando autocrático, inviabilizava a organização e existência de cooperativas.

À medida que os imigrantes europeus começaram a substituir os escravos nas lavouras do Sul do Brasil, já no final do século XIX, o quadro começou a se reverter (AMARAL, 2001).

Assim, as primeiras cooperativas a serem criadas foram as agrícolas e as de consumo e, em seguida, as de crédito. A constituição de 1891 criou o ambiente legal que viabilizou a implantação das cooperativas e consolidou o movimento no País.

Para a OCB (Organização das Cooperativas Brasileiras), as cooperativas baseiam-se em valores de ajuda mútua e responsabilidade, democracia, igualdade, equidade e solidariedade. Na tradição dos seus fundadores, os membros das cooperativas acreditam nos valores éticos da honestidade, transparência, responsabilidade social e preocupação pelo seu semelhante.

A representatividade econômica e social do cooperativismo no Brasil é relevante. Segundo dados da OCB de 2005, conta-se com mais de 7,5 mil cooperativas, reunindo um contingente de cerca de 6,7 milhões associados em todo o País. É responsável por um volume de transações econômicas equivalente a 5\% do Produto Interno Bruto (PIB) e pela geração de 199 mil empregos diretos e outros tantos indiretos. Também é responsável pela interiorização do desenvolvimento social, conseqüentemente, contribuindo para diminuir o êxodo em direção aos grandes centros urbanos.

De acordo com Galerani (2003), o avanço tecnológico tem exigido profissionalização da gestão para o enfrentamento da competição da economia de mercado, devendo desenvolver estratégias de cooperação com tal intuito. Dessa forma, essas organizações se valorizam e melhoram suas condições econômico-sociais. $\mathrm{O}$ autor afirma, ainda, que o acirramento das vantagens competitivas exige das cooperativas estruturas organizacionais enxutas para atender tanto à demanda de seus associados como para se posicionarem positivamente no mercado, tornando-se mais fortes e competitivas.

Amaral (2001, p. 33) destaca que, embora a literatura especializada interprete teoricamente o cooperativismo sob perspectivas de análise diversas, são ainda poucos os estudos empíricos que o focalizam em sua forma institucionalizada, concreta, "como uma "empresa" cooperativa, inserida na dinâmica de uma sociedade capitalista, dando a devida atenção aos fenômenos estruturais e organizacionais internos", que viriam a determinar seus fatores de sucesso.

Em função dessas especificidades, a cooperativa precisa estar apta a participar em igualdade de condições com empresas não-cooperativas, num mercado competitivo e diversificado. Ainda que enfrentando grandes dificuldades, ao passar por um processo de transição política e econômica, redimensionamento e reorganização dos processos, objetivando sua adaptação às regras impostas pelo mercado, essas organizações sobrevivem e continuam atuando de forma específica para garantir sua competitividade. 
Bialoskorski (1997) destaca que a missão fundamental das cooperativas é servir de intermediárias entre o mercado e as economias dos cooperados, para promover o seu incremento.

Atualmente, o segmento depara-se com o desafio de como tornar as cooperativas organizadas e preparadas para atenderem às demandas sociais em sua área de atuação e, ao mesmo tempo, desenvolverem-se em conformidade com o cenário de um mercado altamente competitivo.

Para tanto, são necessárias estratégias específicas que, segundo Farina (1999), são condicionadas pelo ambiente competitivo, no qual são definidos os padrões de concorrência e a capacitação dos recursos internos das empresas. A estratégia seria a competência demonstrada pelas empresas, quer individual ou coletivamente, de modificar favoravelmente algumas das configurações do ambiente competitivo. Para Porter (1999), a conquista e a sustentação da vantagem competitiva ocorrem quando as empresas formulam uma estratégia considerando os fatores básicos que determinam os limites daquilo que podem realizar com sucesso ao enfrentar as forças competitivas do setor, desenvolvendo atividades diferenciadas ou compatibilizando atividades.

As organizações cooperativas, por se caracterizarem como empresas não-lucrativas, são de difícil controle por parte dos cooperados, individualmente ou mesmo pela assembléia geral. Esse é um dos aspectos a ser considerado, bem como sua estrutura doutrinária, por dificultar a gestão; assim, é necessário avaliá-las e trabalhá-las para melhorarem seu desempenho econômico e social. A eficiência dos associados da cooperativa também confere eficiência à própria cooperativa, pois não há como dissociar essas duas organizações. Cada associado é uma empresa que possui o papel de crescer forte em conjunto com o seu empreendimento cooperativo (BIALOSKORSKI NETO, 2000, 2001). Enfim, a qualificação do quadro social faz parte da visão sistêmica, porque contribui para o crescimento de cada um individualmente, dos grupos e da sociedade como um todo.

Por outro lado, a filosofia de atuação e a relação mais claramente estabelecida entre a organização cooperativa e o ambiente político atribuem a esta aspectos específicos de cultura de gestão. Ainda que sua natureza aponte para uma atuação mais transparente a coletiva, Vilela, Carvalho Neto e Lopes (2008), ao compararem os traços de personalidade de dirigentes e cooperativas e de empresas privadas, concluíram que os primeiros têm um perfil mais autoritário de atuação, talvez justificado pela forma de escolha que, nesse caso, se orienta primordialmente pelas questões políticas em detrimento, ou secundarizando as meritocráticas, que ocorrem com mais freqüência nas empresas privadas.

Portanto, as cooperativas atuam em um ambiente fortemente influenciado pela questão política que, por sua vez, estabelece forte ligação entre associado e cooperativa. É nesse contexto que se constroem as relações de lealdade, uma vez que essas organizações compartilham interesses e oferecem possibilidades de mútua sustentação. 


\subsection{Lealdade}

Lealdade é definida como a manifestação positiva do cliente com relação à marca e à empresa, demonstrando o seu comprometimento em uma recompra consistente (SHETH et al., 2001); ou como o grau em que o cliente possui uma atitude positiva, apresenta comprometimento (vínculo emocional) e pretende continuar comprando no futuro (MOWEN e MINOR, 1998). Oliver (1999) define lealdade como um forte comprometimento na recompra de um determinado produto ou serviço, não obstante ser assediado por influências situacionais e esforços de marketing para sugerir comportamento de troca.

Para Oliver (1999), o início do enfoque comportamental da lealdade remonta à década de 70, depois de um período em que a maioria dos autores se referia à lealdade como sendo um padrão de repetição de compras. Os estudos foram evoluindo e se desenvolvendo nas últimas três décadas e, atualmente, o constructo lealdade é, efetivamente, reconhecido pela sua importância no relacionamento com clientes. Assim, várias definições de lealdade foram propostas com ênfase na sua dimensão comportamental.

Day (1969) foi um dos primeiros a apontar o papel da atitude na decisão de compra na lealdade à marca. Conforme o autor, o comportamento de compra por si só não indica uma ligação com uma marca em particular. Deve-se considerar: o efeito das atitudes do cliente e as opções disponíveis no mercado. Dessa forma, além da repetitividade das compras, para ser considerado leal o cliente deve possuir uma atitude positiva em relação ao produto de um fabricante, em relação às demais opções disponíveis no mercado (CURASI e KENNEDY, 2002). A partir da definição de Day (1969), novas definições de lealdade foram propostas, como a de Jacoby e Chesnut (1978) e, mais recentemente, por McMullan e Gilmore (2003), que definem a lealdade do cliente como sendo a escolha de uma marca em particular, entre várias marcas similares, após um processo de decisão e avaliação durante um período.

A lealdade é mais do que um longo relacionamento de um cliente com uma determinada empresa ou visitas freqüentes a um mesmo estabelecimento. Lealdade é um sentimento de afinidade ou ligação com produtos ou serviços de uma empresa; ela se manifesta quando os clientes gastam ou concentram a maior parte ou a totalidade de seus orçamentos com a empresa (DAY, 2001).

A forma comportamental e a forma atitudinal do cliente nem sempre estão positivamente correlacionadas (LARAN e ESPINOZA, 2004), em razão de haver outros fatores de influência além da lealdade no processo de decisão de compra, tais como preço e conveniência (GRACIOSO, 2003; DICK e BASU, 1994). Tais fatores podem causar efeitos substanciais em mercados muito competitivos com pouca diferenciação entre produtos (commodities), o que resulta no surgimento de lealdade falsa determinada por comportamento de compra regular e atitude desfavorável (DICK e BASU, 2003). Nestes mercados com alto nível de 
competitividade - mercado de distribuição de "commodities" - em que os produtos são comuns e de características semelhantes os retornos ocorrem, geralmente, em escala (GRACIOSO, 2003), pequenas atitudes positivas dos fornecedores, direcionadas aos clientes, representam uma contribuição potencialmente significativa para a formação de preferência do cliente no longo prazo, representando um grande benefício para a determinação da lealdade devido à alta competitividade do ambiente (JONES e SASSER, 1995; DICK e BASU, 1994).

Oliver (1999) conceitua lealdade como sendo a existência de comprometimento em efetuar compras repetitivas de um mesmo produto ou serviço; ao assumir esse comportamento o cliente não é influenciável pelos apelos externos da concorrência na busca de incentivá-lo a trocar de fornecedor e, desta forma, romper o relacionamento estabelecido. Hennig-Thurau et al. (2002), complementando, afirmam que a lealdade é mais do que um simples processo de compra repetitivo e se relaciona, de forma direta, com a apreciação e ao comprometimento. Os autores enfatizam que o cliente leal compromete-se com a divulgação da empresa e seus produtos de forma positiva a outros clientes e deixa clara a sua intenção em manter o relacionamento.

Complementarmente, Hennig-Thurau et al. (2002) afirmam que a lealdade é o resultado de vários constructos interligados, sugerindo inclusive uma abordagem holística para a explicação da lealdade. O autor refere-se aos antecedentes da lealdade desenvolvidos por Agustín e Singh (2002), em que, satisfação, confiança e valor, são condutores à lealdade.

Henrique, Monteiro e Matos (2008) também caminham na direção de estabelecer nexos entre os constructos de lealdade com outras dimensões. Consideram que os valores pessoais se constituem em um dos fatores que geram lealdade. Segundo os autores, os indivíduos que compartilham dos mesmos valores respondem de forma semelhante as três fases da lealdade propostas por Oliver.

Mais do que medir lealdade, pesquisadores e profissionais têm demonstrado crescente interesse nos componentes que formam a lealdade do consumidor. De fato, a lógica de que manter clientes atuais requer menor investimento por parte das empresas do que conquistar novos clientes, e que parte significativa dos negócios da empresa é feita com clientes "mais leais", tem levado à priorização de estratégias que construam lealdade e comprometimento. Clientes leais e fiéis à marca proporcionam às empresas a base para participação de mercado estável e crescente e podem representar um importante patrimônio intangível no preço de compra de uma empresa (SHIFFMAN e KANUK, 2000). E ainda, os custos de retenção de clientes podem ser bem menores do que os custos de atração de clientes. Além disso, clientes leais costumam ter maiores gastos com a empresa do que clientes não-leais (SHIFFMAN e KANUK, 2000).

Porém, o desenvolvimento das estratégias de marketing de relacionamento embasado pelas pesquisas e estudos acadêmicos conduziu à constatação de que somente a satisfação dos clientes não seria suficiente para manter relacionamentos, 
o que orientou os pesquisadores a estudarem a relação entre satisfação e lealdade. A satisfação é uma etapa importante e necessária para a formação da lealdade de clientes, mas se torna menos significativa à medida que ela começa a se configurar por meio de outros mecanismos (OLIVER, 1997, 1999).

A partir de então, passou-se a buscar outros fatores, além da satisfação, que seriam responsáveis pela formação da lealdade, tais como preço, qualidade, valor, confiança e atitudes (MITTAL e LASSAR, 1998; PARASURAMAN e GREWAL, 2000; AGUSTING e SINGH, 2002; DICK e BASU, 1994).

Oliver (1997) define a lealdade como um estado de profundo comprometimento com a recompra de um produto ou serviço, consistentemente preferido no futuro, causando, assim, o comportamento repetitivo para com a mesma marca, embora influências situacionais e esforços de marketing e da concorrência desenvolvam estratégias e tenham potencial para provocar e ou causar um comportamento de troca.

Observando essa definição, pode-se reconhecer a lealdade como um forte compromisso para a recompra sustentado por uma preferência forte para o produto ou o serviço. Neste sentido, observam-se ambas as dimensões da lealdade: atitudinal e comportamental. Engel et al. (1995), e também Sheth et al. (2001), reforçam essas dimensões em suas definições da lealdade.

Consequentemente, medir o nível do comprometimento implica considerarem-se as dimensões atitudinal e comportamental. Em estudo, Oliver (1999) apresenta uma estrutura para o conceito da lealdade que faz exame no cliente das três dimensões da atitude (cognitiva-afetiva-conativa) aos quais adiciona a dimensão da ação. Seu trabalho acompanha a estrutura atitudinal de formação da lealdade, argumentando que os três antecedentes da lealdade não precisam ocorrer de forma simultânea para que ela exista. O consumidor pode se tornar leal com base em cada um dos elementos que formam a atitude, caracterizando uma fase distinta da lealdade. $\mathrm{O}$ autor argumenta que $\mathrm{o}$ consumidor pode se tornar leal em cada etapa da dimensão passo a passo.

Para Vieira (2008), a seqüência proposta por Oliver não se aplica a todos os segmentos. No caso do varejo eletrônico, seus estudos sugerem que essas podem se constituir por meio de outros formatos. O primeiro seria: afeto-cognição-conação-ação, quando sentimentos prévios orientam a dimensão cognitiva que finalmente justificariam a decisão de compra, podendo ser compreendida como Hierarquia da Decisão Afetiva, porque a decisão foi baseada em sentimentos de gostar. E o segundo: ação-conação-cognição-afeto, quando não há uma racionalidade prévia que oriente o ato de compra, visto que essa pode ter sido influenciada por outros fatores como tickets, descontos, milhas, etc., nesse sentido, o consumidor irá primeiro se comportar para depois justificar sua ação, só depois gerando cognição e finalmente sentimentos e emoções com relação aquele produto. 
Os estudos dos autores sugerem que a hierarquia do constructo da lealdade varia e, nesse sentido, a seqüência proposta por Oliver não é única.

A distinção entre a lealdade verdadeira e a recompra por inércia é a atitude do consumidor em relação à marca (DICK e BASU, 1994). A lealdade à marca requer uma forte disposição interna do consumidor em continuar comprando a mesma marca (componente atitudinal). Por outro lado, o comportamento de inércia requer apenas um comportamento habitual do consumidor que busca reduzir os esforços físicos e mentais do processo de compra (AMINE, 1998). Para que seja possível detectar a verdadeira lealdade, é necessário avaliar os afetos e as intenções do consumidor dentro da estrutura tradicional de atitude do consumidor (OLIVER, 1999).

$\mathrm{Na}$ literatura, principalmente aquela vinculada à área de marketing, os conceitos de lealdade e fidelidade são tratados ora de forma distinta e, em outras ocasiões, como conceitos muito próximos. Considerando que a definição constitutiva deste trabalho está apoiada no conceito de Oliver (1999) e que este utiliza o termo lealdade, essa será a referência adotada.

Os aspectos ligados à lealdade, por envolverem a incerteza e a complexidade, conduzem as discussões para a economia dos custos de transação.

\subsection{Economia dos Custos de Transação (ECT): a análise da estrutura de governança}

A Economia dos Custos de Transação (ECT) teve origem no trabalho de Coase (1937), a partir da percepção de que na negociação por meio do mercado existem "custos de transação", advindos da busca de informação, negociação e formulação de contratos. Williamson (1985) observa que a decisão de uma transação organizada dentro da firma (hierarquicamente) ou entre firmas autônomas (via mercado) depende dos custos de transação a ela associados.

Uma transação acontece sempre que “(...) um bem ou serviço é transferido através de uma interface tecnologicamente separada. Um estágio de atividade termina e outro começa" (WILLIAMSON, 1985, p. 1). Qualquer transação entre agentes econômicos envolve riscos de que os elementos acordados entre eles não se efetivem. Mecanismos e estruturas de governança são adotados com o objetivo de reduzir tais riscos e suas conseqüências.

Os custos associados à transação estão relacionados aos custos ex ante e ex post. Os primeiros referem-se aos custos de coleta e processamento de informações, de negociações e estabelecimento de salvaguardas. Já os custos após a realização do contrato são de renegociação, monitoramento e de adaptações a circunstâncias não previstas inicialmente. Estes decorrem de dois pressupostos comportamentais: racionalidade limitada e oportunismo. 
A hipótese da racionalidade limitada está relacionada à capacidade cognitiva limitada dos agentes, os quais se presumem sejam racionais, no entanto, apresentam limites frente a um ambiente econômico complexo, além da incerteza imposta pela impossibilidade de antecipar eventos futuros (SIFFERT FILHO, 1995; HIRATUKA, 1997; FARINA, 1997). O oportunismo é definido por Williamson como "a busca do próprio interesse, associada a intenções dolosas de manipular ou distorcer informações de maneira a confundir a outra parte da transação" (NICOLAU, 1994; HIRATUKA, 1997, p. 19). Diante do oportunismo, decorre a incerteza na avaliação do comportamento de outros agentes ligados à transação.

Assim, diante da situação de que os contratos são incompletos, uma vez que se torna impossível prever todas as contingências futuras devido à racionalidade limitada dos agentes, isto implica a possibilidade de comportamentos oportunistas em situações que ocorrem ex post, não previstas no contrato, sem poder prever as conseqüências desse comportamento, fica clara a origem ou a natureza dos custos de transação.

Segundo Souza e Pereira (2006), as diferenças entre as transações (freqüência, incerteza e especificidade do ativo) são definidas como atributos das transações e determinarão o modo de governança mais eficiente.

À medida que aumenta a especificidade do ativo, maiores serão os riscos de perda associados a uma ação oportunista e problemas de adaptação e, consequentemente, maiores são os custos de transação. Caracteriza-se o ativo específico quando a interrupção da transação leva necessariamente a uma perda no valor produtivo desse ativo, mesmo em seu melhor uso alternativo, ou como investimentos não recuperáveis antes do término do contrato. "A especificidade de ativos está diretamente relacionada com a possibilidade de reemprego ou utilização alternativa de um ativo sem que este tenha perda de valor" (VISCONTI, 2001, p. 321).

Em relação à freqüência das transações, diz respeito à regularidade das transações, ou seja, o número de vezes que os agentes realizam transações em determinado período (SOUZA e PEREIRA, 2006). A importância dessa dimensão manifesta-se em vários aspectos: a) diluição dos custos de adoção de um mecanismo complexo por várias transações; b) possibilidade de construção de reputação por parte dos agentes envolvidos na transação (AZEVEDO, 2000); c) redução da incerteza, por meio do conhecimento dos agentes; d) construção de reputação em torno de uma marca; e) criação de um compromisso confiável entre as partes em torno do objeto comum de continuidade da relação.

Farina (1997) distingue três tratamentos diferentes ao conceito de incerteza. O primeiro, dado por Williamson (1991), é denominado por risco e refere-se à variância de uma dada distribuição de probabilidade, dada pela ocorrência de um número maior de distúrbios ou quando os distúrbios tornam-se intrinsecamente mais importantes. O segundo, utilizado por North (1994), corresponde efetivamente ao desconhecimento dos possíveis eventos futuros e, 
o terceiro, dado por Milgrom e Roberts (1992), que enfatizam a assimetria informacional. Sob um ambiente de incerteza, maior é o espaço para renegociação futura e maiores são as possibilidades de perdas derivadas do comportamento oportunista.

Como destaca Hiratuka (1997), a incerteza comportamental ganha mais importância quando as transações incluem ativos específicos. Nestes casos, a continuidade das transações torna-se fundamental e a incerteza adquire dimensão crucial, uma vez que comportamentos oportunistas acarretam maiores custos de transação.

Considerando os pressupostos comportamentais e as dimensões ou atributos das transações, o grau em que estas se apresentam determina a necessidade de se adotar forma organizacional adequada para garantir a continuidade das transações. O desenvolvimento de certas instituições, voltadas à coordenação das transações, resulta de esforços para diminuição dos custos a estas associadas. Busca criar, neste sentido, estruturas de gestão apropriadas, incluindo aquelas que combinam elementos de interação tipicamente mercantil com procedimentos de tipo administrativo (PONDÉ, 1993). Williamson (1985) define, nestes termos, três estruturas de governança: o mercado, a hierarquia e uma forma híbrida (relação contratual).

O mercado é considerado a estrutura mais eficiente quando os ativos específicos não estão presentes. Compradores e vendedores não têm relação de dependência, pois, devido à inexistência ou existência em grau desprezível de ativos específicos, cada um pode estabelecer transações com novos parceiros sem perdas econômicas. Williamson (1985, p. 91) afirma que “(...) o mercado é o modo preferido de suprimento quando a especificidade dos ativos é baixa - em função de problemas burocráticos e de incentivo da organização interna em aspectos de controle de custos de produção". Logo, as partes autônomas realizam transações sem haver desejo de estabelecerem laços contratuais de longo prazo.

A hierarquia ou integração vertical ocorre quando dois ou mais estágios de produção unem-se em uma única firma. Como as operações de produção são realizadas por uma única firma, há um alto poder de adaptabilidade, pelo maior controle de distúrbios e mudanças nos ambientes competitivo, institucional e tecnológico por parte da estrutura hierárquica interna. Entretanto, os custos burocráticos são maiores.

De acordo com a análise de Hiratuka (1997), na medida em que as transações evolvem ativos específicos, a coordenação pelo mercado perde eficiência e surge a necessidade de um mecanismo mais cooperativo, que permita um processo de negociação mais efetivo. É por esta razão que a internalização das atividades dentro da firma torna-se mais vantajosa em termos de custos de transação e adaptabilidade. 
As formas híbridas são aquelas estruturas que se situam entre os extremos do mercado e hierarquia, combinando seus elementos. Em termos transacionais, a funcionalidade e justificativa para a emergência destas estruturas de governança sustentam-se na possibilidade de atenuar os efeitos da incerteza comportamental e de algumas desvantagens da integração vertical, como as distorções burocráticas e as perdas de economias de escala e escopo (PONDÉ, 1993). Mas, conforme afirma Nicolau (1994), perdas de incentivo e aumento no custo de monitoramento forçam a descentralização da atividade e a substituição do controle por incentivos, ou como observa Farina (1997), na medida em que se caminha do mercado em direção à hierarquia, perde-se em incentivo e se ganha em controle.

Assim, a relação entre cooperativas e cooperados envolve custos de transação mediante a realização de contratos. As cooperativas realizam investimentos que necessitam do cumprimento contratual de seus cooperados. De acordo com Zylbersztajn (2002, p. 15), "a quebra contratual ex post leva à perda de valor dos ativos investidos, dificultando o planejamento de longo prazo e a estabilidade das relações entre as partes". Portanto, o comportamento desleal dos cooperados caracterizado por ações oportunistas leva a um aumento dos custos de transação. $\mathrm{O}$ autor destaca que o estudo comparativo da eficiência da organização cooperativa é um campo ainda a ser aprofundado; por exemplo, em quais circunstâncias a organização cooperativa é mais eficiente do que a firma com fins lucrativos? (ZYLBERSZTAJN, 2005).

\section{Metodologia}

Trata-se de uma pesquisa exploratória, com tipologia seccional, uma vez que tratou do momento atual, cujos níveis de análise foram o indivíduo e a organização (VIEIRA e DEBORAH, 2004).

Quanto ao meio de investigação, utilizou-se pesquisa de campo por meio de um questionário. A definição operacional deste instrumento foi organizada através de duas questões em escala de cinco pontos que identificavam o grau de importância atribuído pelo respondente, partindo de 1 (altamente importante) até 5 (nenhuma importância). Tal escala objetivou a busca de informações sobre o grau de influência de cada variável sobre a lealdade dos cooperados. Contou ainda com 7 questões abertas que trataram de questionamentos que identificavam situações em que se verifica a deslealdade (conceito, contexto, perfil e a atuação).

A definição constitutiva que orientou a seleção das categorias de análise foi baseada em Oliver (1999) que conceitua lealdade como sendo a existência de comprometimento que conduz a um comportamento em que o cliente não é influenciável pelos apelos externos da concorrência, inibindo a troca de fornecedor e, desta forma, rompe o relacionamento estabelecido. Tal conceito examina o 
cliente em três dimensões da atitude: cognitiva-afetiva-conativa. Para que seja possível detectar a verdadeira lealdade, é necessário avaliar os afetos e as intenções do consumidor dentro da estrutura tradicional de atitude do consumidor.

Adequando tal referência ao contexto da pesquisa, utilizou-se o seguinte enunciado: lealdade, no ambiente cooperativo, representa o cumprimento de um compromisso que envolve a dimensão cognitiva-afetiva-conativa de forma recíproca entre o associado e a organização, no intuito de estabelecer uma relação de permanência em que a influência de apelos externos não afete a relação. Do ponto de vista de sua percepção, avalia-se a atitude tanto do cooperado como do dirigente da cooperativa.

A coleta dos dados foi realizada em cooperativas localizadas no estado de Santa Catarina (regiões oeste e planalto sul) e interior de São Paulo (região de Campinas). A definição das regiões deu-se em função da importância do cooperativismo para as atividades econômicas desenvolvidas, quais sejam: o agronegócio de carnes e leite no oeste catarinense; serviços no planalto sul catarinense; e floricultura na região de Campinas.

A amostra foi constituída por cooperativas classificadas como agrícola, agropecuária, infra-estrutura, serviços e de crédito, na sua maioria, de médio e grande porte.

Os questionários foram aplicados pelos pesquisadores diretamente aos produtores rurais cooperados e aos dirigentes de cooperativas, seguindo o critério de acessibilidade e exaustão. Responderam o questionário 25 cooperados e 12 dirigentes. Conforme Vergara (1998), neste caso, são selecionados elementos pela facilidade de acesso a eles. A exaustão foi considerada quando as respostas tornaram-se repetitivas e não se obtinha novos dados ou informações relevantes. A análise dos dados considerou as categorias constantes no Quadro 1.

O Quadro 2 relaciona as dimensões de atitude propostas na definição constitutiva, com as variáveis de análise. Tal agrupamento tem como objetivo contribuir no processo de interpretação dos dados. Para análise dos dados foram utilizadas a estatística descritiva e a análise interpretativa para as questões descritivas. 
Quadro 1. Foco de análise de variáveis utilizadas para a verificação do grau de importância sobre a lealdade em cooperativas.

\begin{tabular}{|l|l|}
\hline Variável & Foco de análise \\
\hline Preço & Preços pagos aos cooperados na comercialização de seus produtos. \\
\hline Atendimento & $\begin{array}{l}\text { Qualidade prestada no atendimento ao cooperado no momento } \\
\text { em que ele procura a cooperativa para efetuar qualquer objetivo. }\end{array}$ \\
\hline Crédito & $\begin{array}{l}\text { Oferecimento de linhas de crédito seja para operações de curto } \\
\text { prazo, tais como alimentos, medicamentos veterinários, etc., ou } \\
\text { com prazos maiores para financiamento de safra ou investimentos. }\end{array}$ \\
\hline $\begin{array}{l}\text { Condições de } \\
\text { pagamento }\end{array}$ & $\begin{array}{l}\text { Formas de pagamentos na aquisição de produtos: à vista, } \\
\text { parcelamentos, etc. }\end{array}$ \\
\hline Cota-capital & $\begin{array}{l}\text { Recolhimento de parcela das transações comerciais para uma conta } \\
\text { específica, resultando na formação da "cota-capital". }\end{array}$ \\
\hline Confiança & $\begin{array}{l}\text { Nível de confiança estabelecida entre o associado e os dirigentes } \\
\text { diretamente ligados a ele. }\end{array}$ \\
\hline $\begin{array}{l}\text { Produtos e } \\
\text { serviços }\end{array}$ & $\begin{array}{l}\text { Quantidade e disponibilidade de produtos e serviços oferecidos ao } \\
\text { cooperado. }\end{array}$ \\
\hline Qualidade & Qualidade dos produtos oferecidos para a comercialização. \\
\hline Prazo & Entrega de produtos nos prazos estabelecidos. \\
\hline $\begin{array}{l}\text { Utilidade/ } \\
\text { satisfação }\end{array}$ & $\begin{array}{l}\text { Nível de utilidade e satisfação obtida pelos cooperados na } \\
\text { utilização dos serviços da cooperativa. }\end{array}$ \\
\hline $\begin{array}{l}\text { Assistência } \\
\text { técnica }\end{array}$ & Serviços de assistência técnica oferecida ao cooperado. \\
\hline Cultura & $\begin{array}{l}\text { Aspectos relacionados à cultura do cooperado: relações de } \\
\text { amizade, encontros recreativos, atividades de ajuda mútua, } \\
\text { eventos esportivos, solidariedade. }\end{array}$ \\
\hline $\begin{array}{l}\text { Imagem } \\
\text { institucional }\end{array}$ & $\begin{array}{l}\text { Grau de importância e influência da marca da cooperativa perante } \\
\text { o mercado e a transferência dessa para o cooperado. }\end{array}$ \\
\hline
\end{tabular}

Fonte: Elaborado pelos autores.

Quadro 2. Relação entre a dimensão da atitude e a variável de análise.

\begin{tabular}{|l|l|}
\hline Dimensões de atitude & Variável de análise \\
\hline $\begin{array}{l}\text { Cognitiva (CG): refere-se ao grau } \\
\text { de informação e conhecimento }\end{array}$ & $\begin{array}{l}\text { Atendimento, qualidade, utilidade/satisfação, } \\
\text { assistência técnica }\end{array}$ \\
\hline $\begin{array}{l}\text { Afetiva (AF): forma de emoções, } \\
\text { sentimentos e paixões }\end{array}$ & $\begin{array}{l}\text { Atendimento, confiança, utilidade/satisfação, } \\
\text { assistência técnica, cultura, imagem } \\
\text { institucional, cota-capital }\end{array}$ \\
\hline $\begin{array}{l}\text { Conativa (CN): tendência } \\
\text { consciente para atuar }\end{array}$ & $\begin{array}{l}\text { Preço, atendimento, crédito, condição de } \\
\text { pagamento, cota-capital, produtos e serviços, } \\
\text { prazo }\end{array}$ \\
\hline
\end{tabular}

Fonte: Elaborado pelos autores. 


\section{Resultados e discussão}

A pesquisa realizada no ambiente cooperativo apresentou diferentes percepções dos gestores e associados quanto ao aspecto da lealdade, que serão apresentadas a seguir no Gráfico 1.

Pode-se perceber que, para $75 \%$ dos dirigentes e para $56 \%$ dos cooperados que responderam aos questionários, os associados às cooperativas apresentam um comportamento relativamente leal. Isso demonstra que a maior parte dos cooperados, mesmo que ocasionalmente, incorre em deslealdade para com a sua cooperativa. Isso fica evidenciado pela indicação dos cooperados respondentes, de que $8 \%$ dos associados apresentam comportamento pouco leal. Já para cerca de $25 \%$ a $35 \%$ dos dirigentes e cooperados, respectivamente, os sócios possuem perfil de alta lealdade.

Nessa perspectiva, os agentes externos exercem influência e, assim, interferem na lealdade. De outra forma, também é possível salientar que as relações entre os cooperados e as cooperativas podem ser analisadas sob a ótica do oportunismo, que Williamson define como "a busca do próprio interesse, associada a intenções dolosas de manipular ou distorcer informações de maneira a confundir a outra parte da transação" (NICOLAU, 1994; HIRATUKA, 1997, p. 19). Essa questão será retomada quando analisado os fatores que os entrevistados caracterizam como ações desleais.

Gráfico 1. Percepção de dirigentes e cooperados quanto ao grau de lealdade dos cooperados.

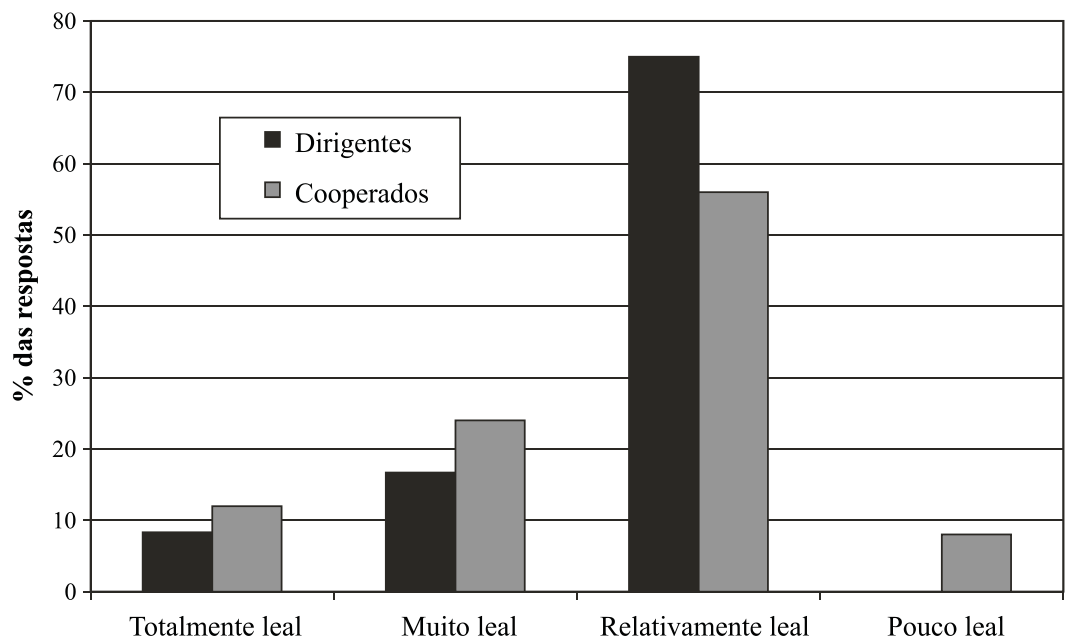

Fonte: Pesquisa de campo (fevereiro de 2007). 
Os fatores responsáveis pela lealdade dos cooperados avaliados por dirigentes de cooperativas e por cooperados são apresentados no Quadro 3. De maneira geral, tanto dirigentes quanto cooperados consideram que todas as variáveis selecionadas apresentam muita importância na determinação da lealdade, com destaque, no caso dos cooperados, para a confiança e no dos dirigentes, além da confiança, para qualidade e assistência técnica. Nesse caso, a variável de análise que representa maior grau de importância para as duas categorias de entrevistados é a confiança que, no Quadro 2, foi relacionada à afetividade.

Quadro 3. Percepção de dirigentes e cooperados sobre o grau de importância de variáveis selecionadas sobre a lealdade em cooperativas.

\begin{tabular}{|c|c|c|c|c|c|}
\hline \multirow{3}{*}{$\begin{array}{l}\text { Dimensões } \\
\text { de atitude }\end{array}$} & \multirow{3}{*}{ Variável } & \multicolumn{4}{|c|}{ Grau de importância } \\
\hline & & \multicolumn{2}{|c|}{ Dirigentes } & \multicolumn{2}{|c|}{ Cooperados } \\
\hline & & Média & Moda & Média & Moda \\
\hline $\mathrm{CG} ; \mathrm{AF} ; \mathrm{CN}$ & Atendimento & 1,5 & 2 & 1,6 & 2 \\
\hline $\mathrm{AF}$ & Confiança & 1,3 & 1 & 1,7 & 1 \\
\hline CG & Qualidade & 1,5 & 1 & 1,7 & 2 \\
\hline $\mathrm{CN}$ & Prazo & 1,8 & 2 & 1,7 & 2 \\
\hline $\mathrm{CN}$ & Crédito & 2,4 & 2 & 1,9 & 2 \\
\hline $\mathrm{AF}$ & Imagem & 1,9 & 2 & 1,9 & 2 \\
\hline $\mathrm{CN}$ & Preço & 1,7 & 2 & 2,0 & 2 \\
\hline $\mathrm{CN}$ & Condições de pagamento & 2,6 & 3 & 2,0 & 2 \\
\hline $\mathrm{CG} ; \mathrm{AF}$ & Utilidade/satisfação & 1,8 & 2 & 2,0 & 2 \\
\hline $\mathrm{CN}$ & Produtos e serviços & 1,8 & 2 & 2,1 & 2 \\
\hline $\mathrm{CN} ; \mathrm{AF}$ & Assistência técnica & 1,9 & 1 & 2,1 & 2 \\
\hline $\mathrm{AF} ; \mathrm{CN}$ & Cota-capital & 2,5 & 2 & 2,3 & 2 \\
\hline \multirow[t]{2}{*}{$\mathrm{AF}$} & Cultura & 2,6 & 2 & 2,6 & 2 \\
\hline & Média geral & 1,95 & - & 1,97 & - \\
\hline
\end{tabular}

Fonte: Pesquisa de campo (fevereiro de 2007).

Notas: 1) Escala utilizada para avaliação do grau de importância: 1 - altamente importante; 2- muito importante; 3 relativamente importante; 4 - pouco importante; e 5 - nenhuma importância.

2) $\mathrm{CG}$ - cognitivo; $\mathrm{AF}$ - afetivo e $\mathrm{CN}$ - conativo.

A percepção dos dirigentes e cooperados no conjunto das respostas é relativamente semelhante apresentando um alto coeficiente de correlação linear simples entre as médias $(\mathrm{r}=0,7237)$, indicando que não há distorções entre a percepção dos associados e da cooperativa.

As variáveis mais importantes para a lealdade são: atendimento, confiança, qualidade, prazo, crédito e imagem, que se relacionam de forma equilibrada com as dimensões de atitude cognitiva, afetiva e conativa. Na percepção dos cooperados, as variáveis crédito, condições de pagamento e cota-capital 
apresentam grau de importância médio maior do que na percepção dos dirigentes, vinculadas, portanto, predominantemente à dimensão conativa, implicando diretamente na decisão por manter ou não a lealdade.

A análise dos dados possibilita uma interpretação do significado simbólico que os entrevistados têm construído sobre o cooperativismo. Considerando que o valor central dessa proposta organizacional está vinculado a valores relacionados à solidariedade, se poderia supor que as dimensões da afetividade obtivessem maior evidência na percepção. Contudo, com exceção da confiança, isso não ocorreu.

Nesse sentido, pode-se deduzir que as variáveis que interferem mais diretamente na ação dos cooperados estão vinculadas a valores do mercado, tais como preço, crédito, condições de pagamento. Tanto que a variável da cultura, que está relacionada aos valores do cooperativismo de forma mais direta, encontra uma média coincidente entre cooperados e dirigentes com menor nível de importância.

Isto significa dizer que não parece existir, de forma muito evidente, uma sustentação valorativa suficientemente sólida que possibilite ausência de contratos que orientem as transações. Do ponto de vista dos custos de transação, pode-se inferir que a ausência de um compromisso confiável entre as partes em torno do objeto comum pode comprometer a continuidade da relação, elevando os custos.

Tal situação sugere que a consolidação da atuação cooperativa relacionada à construção do capital social, que segundo Dalmoro, Klein, Wittmann e Batistella (2008) reduziriam os custos de transação, não parece fortemente presente nesse ambiente. Evidencia-se a contraditoriedade dessa questão se considerada a referência que na percepção dos entrevistados a dimensão da confiança ficou evidenciada.

Para os dirigentes de cooperativas, o cooperado fiel é aquele que apresenta as seguintes características:

- Comercializa toda sua produção com a cooperativa;

- É participativo, sejam em reuniões, assembléias, eventos e ações promovidas pela cooperativa, como também nas manifestações apontando falhas e sugerindo melhorias;

- Confia e defende a cooperativa, colaborando para seu bom funcionamento;

- Cumpre seus deveres e exige seus direitos, conforme o estatuto;

- Valoriza a cooperativa.

Na percepção de $70 \%$ dos cooperados, ser fiel é comprar e vender na cooperativa, ou seja, realizar suas operações somente com ela. $\mathrm{O}$ entendimento de que o cooperado deve apresentar confiança e ser participativo nas ações foi citado por poucos entrevistados.

Percebe-se que a perspectiva de lealdade presente no discurso dos dirigentes é mais ampla e envolve a dimensão cognitiva e afetiva, ao resgatar os princípios do cooperativismo como orientadores da relação entre cooperados e cooperativa. 
Do ponto de vista dos associados, a relação é mais pragmática, pois não envolve de forma significativa a dimensão subjetiva ou não expressa valores que visam à construção de um tipo de organização diferenciada, mas, sobretudo, uma relação contratual de negócios de exclusividade que pouco valoriza outras possibilidades de socialibilidade oferecidas pelo contexto cooperativista.

Nesse sentido, o conceito que lealdade proposto por Day (2001) que a relaciona com afinidade não parece estar presente, tampouco a proposta de Henrique, Monteiro e Matos (2008) que discutem a dimensão dos valores pessoais.

Já o típico cooperado desleal, para os dirigentes, é aquele que reclama por melhores preços, seja na ocasião da compra ou na venda de produtos e serviços, comercializando sua produção com outras empresas, o que procura a cooperativa em situações em que pode obter vantagens e apresenta comportamento individualista, com pouca participação nas ações coletivas.

Para os cooperados, a deslealdade é percebida quando:

- Compra e vende em outros estabelecimentos comerciais;

- Não participa das atividades desenvolvidas pela cooperativa;

- Busca obter vantagens oferecidas pela cooperativa, tais como o crédito;

- Atua em várias atividades, inclusive na comercialização de produtos;

- Apresenta débitos com a cooperativa.

A deslealdade, na percepção dos dirigentes, ocorre nas situações em que o cooperado encontra-se com dificuldades financeiras, determinadas por atrasos de pagamento de seus financiamentos. Nestes casos, a comercialização da produção com a cooperativa implica no "seqüestro" da receita em função dos débitos presentes, situação em que o cooperado busca outras opções para a solução de seus problemas. Outra causa de deslealdade é a ocorrência de preços melhores em outras empresas, seja para a compra de insumos ou para a comercialização de sua produção.

A maior parte das ocorrências de deslealdade, na compreensão dos cooperados, ocorre principalmente quando ele encontra preços mais competitivos em outros estabelecimentos. Outros fatores também são citados, tais como: ocorrência de prazos de pagamento não-adequados, débitos com a cooperativa e falta de linhas de crédito.

Portanto, as ações de deslealdade estão relacionadas a situações em que a sobrevivência ou os interesses individuais são colocados em risco em detrimento de um projeto coletivo. Neste caso, a ação do cooperado rompe o contrato de confiança e estabelece uma atuação de autodefesa, que se poderia caracterizar, no contexto da teoria da agência, como uma relação oportunista, ou seja, "a busca do próprio interesse, associada a intenções dolosas de manipular ou distorcer informações de maneira a confundir a outra parte da transação" (NICOLAU, 1994; HIRATUKA, 1997, p. 19). 
Para aumentar a lealdade dos cooperados, os dirigentes realizam as seguintes ações:

- Atuação na área de transferência de tecnologia: assistência técnica, treinamentos e qualificação (8);

- Transparência e informações corretas sobre suas ações (6);

- Bom atendimento e qualidade dos produtos e serviços oferecidos (3);

- Pontualidade nos pagamentos (3);

- Distribuição das sobras do exercício (em dinheiro e capitalizado) (2);

- Realização de ações com esposas e filhos de cooperados, integrando-os às ações da cooperativa (2);

- Crédito para plantio com pagamento na colheita (1);

- Realização de programas sociais (1).

As ações desenvolvidas pelas cooperativas na promoção da lealdade, na percepção dos cooperados, são: bom atendimento aos associados, assistência técnica e formação, fornecimento de crédito, bons prazos de pagamento e desenvolvimento de ação social.

Esses dados sugerem que diante da impossibilidade de um enfrentamento direto com o mercado no que diz respeito à questão de preço e às condições de pagamento, as cooperativas buscam minimizar essa relação deficitária através de apoio tecnológico, seguido por idoneidade de relações. Tal percepção é compartilhada pelos cooperados.

O envolvimento de toda a família do cooperado nas ações da cooperativa, nos aspectos sociais, de saúde e educação no meio rural, na visão dos dirigentes, contribui para a obtenção de melhores resultados econômicos e para a maior qualidade de vida. Tais ações promovem maior satisfação dos produtores com a cooperativa, aumentando sua lealdade. Os cooperados também apontam essa vertente ao destacarem a dimensão da ação social.

De modo geral, as ações para desenvolver a maior lealdade dos cooperados passam por uma educação cooperativa, visando à conscientização sobre a importância do cooperativismo como forma de organização dos produtores. Contudo, como visto no Quadro 3, a dimensão cultural encontra-se em um nível de importância menor do que todas as outras variáveis.

Saliente-se ainda que, conforme apontado por Prates e Barros (2006), as relações no contexto da cultura organizacional brasileira, no que diz respeito aos líderes, são desenvolvidas em dois eixos, o paternalismo e o personalismo, que privilegiam relações pessoais em detrimento das formais e coletivas. 
Para os cooperados que apresentam comportamento infiel, os procedimentos adotados pelas cooperativas, segundo os dirigentes, são:

- Limitação das operações de acesso a crédito;

- Limitação do acesso a assistência técnica, treinamentos e demais ações sociais;

- Realização de trabalhos de recuperação, prestando esclarecimentos sobre as vantagens de atuar com a cooperativa, convidando o sócio a participar das ações desenvolvidas e a tornar-se fiel;

- Exclusão do quadro de associados quando persiste comportamento infiel.

As ações indicadas parecem ter um caminho unilateral, uma vez que a deslealdade é vista sob a ótica de um desvio de conduta do cooperado e não como um problema a ser discutido no interior da lógica da estrutura cooperativa.

Na percepção dos cooperados, as ações que poderiam ser adotadas para estimular a lealdade nas cooperativas são:

- Obtenção de melhores preços, tanto dos insumos quanto da produção;

- Retorno da cota-capital;

- Atendimento das necessidades dos cooperados no que se referem a crédito, taxas de juros e condições de pagamento;

- Bom atendimento e relacionamento com os cooperados;

- Maior apoio às questões de saúde dos cooperados;

- Formação e profissionalização dos cooperados;

- Inclusão da matéria de cooperativismo na estrutura curricular do ensino fundamental;

- Conscientização sobre a importância das cooperativas como instrumento dos produtores;

- Transparência das ações da diretoria;

- Controle conforme rege o estatuto.

No caso dos cooperados, a reconstrução da lealdade está apoiada em mudanças internas na estrutura cooperativa do ponto de vista de sua competitividade com o mercado e do atendimento das necessidades básicas do cooperado no que diz respeito a sua sobrevivência imediata. Nesse sentido, enquanto o foco dos dirigentes pretende uma modelação no comportamento do cooperado, no caso destes o foco é a modelação da cooperativa de acordo com os interesses individuais.

Novamente é perceptível a questão do oportunismo nas duas esferas, dos dirigentes e dos cooperados, visto que a lealdade está condicionada à manutenção do status quo de cada um, relegando os valores cooperativistas de igualdade, coletividade e solidariedade a um segundo plano.

Tal dicotomia pode se constituir em uma elevação dos custos de transação, uma vez que as relações de confiança não são fortalecidas. 


\section{Conclusões e recomendações}

O objetivo deste estudo foi analisar como dirigentes e cooperados percebem os fatores que contribuem na construção de relações de lealdade com a cooperativa.

As cooperativas estão inseridas, via de regra, em um ambiente institucional altamente competitivo, em alguns casos de forma mais intensa, como as agrícolas, agropecuárias e de crédito, e em outros menos, como as de infra-estrutura e serviços.

A competitividade do ambiente institucional, aliada aos pressupostos comportamentais dos agentes caracterizados por uma forte tendência em preservar sua sobrevivência por meio da autodefesa em detrimento de ações coletivas, implica na necessidade de uma atuação diferenciada das cooperativas em relação à construção de relações de lealdade mais estáveis.

A lealdade conduz ao estabelecimento de vínculos de permanência suficientemente fortes, a ponto de serem resistentes à influência do meio externo. Quando esta dimensão valorativa é confrontada pela institucional torna-se necessário o estabelecimento de reajustes contratuais capazes de manter o relacionamento leal, mas sem transgredirem de forma significativa o interesse dos agentes.

Existe na relação entre dirigentes e cooperados uma tendência ao atendimento das demandas individuais, que caracterizam o oportunismo recíproco, em detrimento daquelas derivadas da filosofia cooperativista.

No caso das cooperativas, o acirramento competitivo não foi acompanhado por novas relações contratuais que possibilitassem a ela uma salvaguarda de seus interesses, uma vez que, quando as relações de lealdade não são mantidas, esta não tem instrumentos suficientemente fortes para romper o contrato ou restabelecer os padrões de lealdade necessários à relação.

Por outro lado, uma vez rompida a lealdade, essas organizações não conseguem renegociar, em um tempo viável, as adaptações necessárias à manutenção de um relacionamento, ainda que em diferentes patamares do que aqueles originalmente contratados.

As ações previstas pelos dirigentes quase sempre lidam com a possibilidade de convencimento dos associados a retornarem para uma estrutura pré-estabelecida, que normalmente não atendem de forma satisfatória os interesses dos associados, por meio de processos por eles denominados como de educação ou conscientização.

Contudo, os associados indicam de forma incisiva que a freqüência das trocas contratuais entre eles e a cooperativa, só pode ser mantida se atingir o patamar de concorrência estabelecido no mercado, de forma a não afetar negativamente a rentabilidade da atividade produtiva desse agente.

O estudo demonstrou que o surgimento de relações oportunistas não é decorrente unicamente de um desvio comportamental dos associados, mas, também, é fruto de uma relação entre o ambiente institucional e as organizações cooperativas, que não conseguem responder adequadamente a essas demandas. $\mathrm{Na}$ tentativa de manter uma auto-imagem diferenciada (solidariedade, ajuda 
mútua, coletividade, em detrimento de relações rentáveis) da lógica do mercado em que estão inseridas, afastam-se das possibilidades de manter as relações de lealdade, uma vez que estas comprometem a sobrevivência dos agentes.

É o que apontam os cooperados ao sugerirem que a manutenção da lealdade depende de uma reorganização da cooperativa no que diz respeito às oportunidades que estão presentes no mercado e àquelas oferecidas pela cooperativa.

Nesse sentido, para manter relações de lealdade, seria necessária uma revisão das relações contratuais ex ante e ex post e, em um segundo momento, avaliar as possibilidades de alinhamento ou de constituir nichos de mercado no contexto do ambiente institucional.

\section{Referências Bibliográficas}

AGUSTIN, C.; SINGH, J. Satisfaction, trust, value and consumer loyalty: curvilinearities in relationship dynamics. In: CONFERENCE OF EUROPEAN MARKETING ACADEMY, 31., 2002, Portugal. Anais... Portugal, 2002.

AMARAL, A. M. Fatores críticos de sucesso de organizações cooperativas. Belo Horizonte: UFMG, 2001.

AMINE, A. Consumers'true brand loyalty: the central role of commitment. Journal of Strategic Marketing, v. 6, 1998.

AZEVEDO, P. F. Nova economia institucional: referencial geral e aplicações para a agricultura. Agricultura, São Paulo, n. 47, p. 33-52, 2000.

BIALOSKORSKI, S. N. Cooperativas: economia, crescimento e estrutura de capital. 1997. 257 f. Tese (Doutorado) - Escola Superior de Agricultura "Luiz de Queiroz", Universidade de São Paulo, Piracicaba, 1997.

BIALOSKORSKI NETO, S. Agribusiness cooperativo. In: ZILBERSZTAJN, D.; NEVES, M. P. O. Economia e gestão de negócios agroalimentares. São Paulo: Pioneira, p. 235 - 253, 2000.

BIALOSKORSKI NETO, S. Agronegócios cooperativos. In: BATALHA, M. O. Gestão agroindustrial. São Paulo: Atlas, 2001, p. 628-654.

COASE, R. H. The nature of the firm. Economica, v. 4, p. 386-405, 1937.

COOK, M. L. The future of U.S. agricultural cooperatives: a neo-institutional approach. American Journal of Agricultural Economics. v. 77, n. 5, p. 1153-1159, 1995.

CURASI, C. F.; KENNEDY, K. N. From prisoners to apostles: a typology of repeat buyers and loyal customers in service businesses. The Journal of Services Marketing, v. 16, n. 4, p. 322-341, 2002. 
DALMORO, M.; KLEIN, L. L.; WITTMANN, M. L.; BATTISLELLA, L. F. A presença de capital social em organizações da natureza cooperativa. In: ENCONTRO DE ESTUDOS ORGANIZACIONAI, 5., 2008, Belo Horizonte. Anais... Belo Horizonte: ANPAD, 2008.

DAY, G. S. A empresa orientada para o mercado: compreender, atrair e manter clientes valiosos. Bookman, 2001.

DAY, G. S. A two-dimensional concept of brand loyalty. Journal of Advertising Research, v. 9, n. 3, p. 29-35, 1969.

DICK, A.; BASU, K. Customer loyalty: toward an integrated conceptual framework. Journal of the Academy of Marketing Science, v. 22, n. 2, p. 99-113. 1994.

ENGEL, J. F.; BLACKWELL R. D.; MINIARD, P. W. Consumer behavior. Fort Worth: The Dryden Press, 1995.

FARINA, E. M. M. Q. Abordagem sistêmica dos negócios agroindustriais e a economia dos custos de transação. In: FARINA, E. M. M. Q., AZEVEDO, P. F., SAES, M. S. M.. Competitividade: mercado, estado e organizações. São Paulo: Singular, 1997. p. 165-176.

FARINA, E. M. M. Q. Competitividade e coordenação dos sistemas agroindustriais: a base conceitual. In: JANK, M. S.; FARINA, E. M. Q.; GALAN, V. B. O agrobusiness do leite no Brasil. São Paulo: Milkbizz, 1999.

GALERANI, J. Formação, estruturação e implementação de aliança estratégica entre empresas cooperativas. RAE eletrônica, v. 2, n. 1, jan./jun. 2003.

GRACIOSO, F. Top of mind: na prática, a teoria é outra. Marketing, ano 37, n. 361, p. 35-41, 2003.

HENNIG-THURAU, T.; GWINNER, K.; GREMLER, D. Understanding relationship marketing outcomes: an integration or relational benefits and relational quality. Journal of Service Research, v. 4, n. 3, p. 230-247, 2002.

HENRIQUE J. L.; MONTEIRO, P. R. R.; MATOS, C. A. de. As influências dos valores pessoais nas atitudes e nas fases da lealdade. In: ENCONTRO DE MARKETING DA ANPAD, 3., 2008, Curitiba. Anais.... Curitiba: ANPAD, 2008.

HIRATUKA, C. Estruturas de coordenação e relações interfirmas: uma interpretação a partir da teoria dos custos de transação e da teoria neo-schumpeteriana. Economia da Empresa, São Paulo, v. 4, n. 1, p. 17-32, 1997.

IRION, J. E. Cooperativismo e Economia Social. São Paulo: STS, 1997.

JACOBY, J.; CHESNUT, R. W. Brand loyalty measurement and management. New York, NY: Wiley, 1978. 
JONES, T. O.; SASSER, W. E. Jr. Why satisfied customers defect. Harvard Business Review, v. 73, p. 88-99, nov./dec. 1995.

KNUTSON, R. D. Cooperatives and the competitive ideal. Journal of Farm Economics. v. 48, n. 3, p. 111-121, 1966.

LARÁN, J. A.; ESPINOZA, F. S. Consumidores satisfeitos, e então? analisando a satisfação como antecedente da lealdade. Revista de Administração Contemporânea, v. 8, n. 2, p. 51-70, abr./jun. 2004.

LEZAMIZ, M. Relato breve del cooperativismo. Textos Básicos de Otalora. Área de educación y difusión cooperativa. 1993. Disponível em: <http://www. mondragon.mcc.es/esp/informacion/publicaciones.html>. Acesso em: 05 mai. 2005.

MACHADO FILHO, C. A. et al. Gestão estratégica em cooperativas agroindustriais. Caderno de Pesquisas em Administração, São Paulo, v. 11, n. 2, p. 61-69, abr.jun. 2004.

McMULLAN, R.; GILMORE, A. The conceptual development of customer loyalty measurement: a proposed scale. Journal of Targeting, Measurement and Analysis for Marketing, v. 11, n. 3, 2003.

MILGROM, P.; ROBERTS, J. Economics: organizations and menagement. Prentice Hall International Editions, 1994, 621p.

MITTAL, B; LASSAR, W. M. Why do customers switch? the dynamics of satisfaction versus loyalty. The Journal of Services Marketing, v.12, n. 3, 1998.

MORGAN, R. M. e HUNT, S. D. The commitment - trust theory of relationships marketing. Journal of Marketing, jul. 1994.

MOWENN, J. C.; MINOR, M. Consumer behavior. $5^{\mathbf{a}}$ ed. Upper Saddle River. Prentice-Hall, 1998.

NICOLAU, J. A. A organização das cadeias agroindustriais de arroz irrigado e frango de corte: uma abordagem de custos de transação. São Paulo, 1994. 188 f. Tese (Doutorado em Economia) - FEA/IPE - Universidade de São Paulo.

NORTH, D. C. Institucions, institucional change and economic performance. Gambridge University Press, 1994. 152 p.

ORGANIZAÇÃO DAS COOPERATIVAS BRASILEIRAS - OCB. Disponível em: $<$ www.brasilcooperativo.com.br>. Acesso em 15 fev. 2007.

OLIVEIRA, D. de. P. R. de. Manual de Gestão das Cooperativas: uma abordagem prática. São Paulo: Atlas, 2001. 
OLIVER, R. L. Satisfaction: a behavioral perspective on the consumer. Irwin/McGraw-Hill, New York, 1997.

OLIVER, R. L. Whence consumer loyalty. Journal of Marketing, v. 63, p. 33-44 Special Issue, 1999.

PARASURAMAN, A.; GREWAL, D. The impact of technology on the quality-value-loyalty chain: a research agenda. Journal of Academy of Marketing Science, v. 1. n. 28, 2000.

PINHO, D. B. Economia e cooperativismo. São Paulo: Saraiva, 1977.

PONDÉ, J. L. Coordenação e aprendizado: elementos para uma teoria das inovações institucionais nas firmas e nos mercados. Campinas, 1993. Dissertação (Mestrado em Economia) - Universidade Estadual de Campinas.

PORTER, M. E. Competição: estratégias competitivas essenciais. Rio de Janeiro: Campus, 1999.

PRATES, M. A. S e BARROS, B. T. O estilo brasileiro de administrar: sumário de um modelo de ação cultural brasileiro com base na gestão empresarial. In: MOTTA, F.P. E CALDAS, M. Cultura Organizacional e Cultura Brasileira. São Paulo: Atlas, 2006.

SCHIFFMAN, G. L.; KANUK, L. L. Comportamento do consumidor. Rio de Janeiro: LTC, 2000.

SHETH, J. N.; MITTAL, B.; NEWMAN, B. I. Comportamento do cliente: indo além do comportamento do consumidor. São Paulo: Atlas, 2001.

SIFFERT FILHO, N. F. A Economia dos custos de transação. Revista do BNDES, Rio de Janeiro, v. 2, n. 4, p. 103-128, 1995.

SOUZA, J. P. de; PEREIRA, L. B. Elementos básicos para estudo de cadeias produtivas: tratamento teórico-analítico. In: SIMPÓSIO DE ENGENHARIA DE PRODUÇÃO, 13., 2006, Baurú. Anais... Baurú: SIMPEP, 2006.

VERGARA, S. C. Projetos e relatórios de pesquisa em administração. São Paulo: Atlas, 1998.

VIEIRA, M. M. F.; DEBORAH, M. Z. (Org.). Pesquisa qualitativa em administração II. Rio de Janeiro: Editora FGV, 2005.

VIEIRA, V. A. A. Afinal existem outras seqüências para o esquema teórico de Oliver (1999): cognição, afeto, conação e ação? In: ENCONTRO NACIONAL DA ANPAD, 32., 2008, Rio de Janeiro. Anais ... Rio de Janeiro: ANPAD, 2008. 
VILELA, J. R. de P. X.; CARVALHO NETO, A.; LOPES, H. E. G. Dirigente de empresas privadas e de cooperativas: quem é mais autoritário? uma visão do poder nas organizações baseada na escala " $\mathrm{F}$ " de adorno. In: ENCONTRO DE ESTUDOS ORGANIZACIONAI, 5., 2008, Belo Horizonte. Anais... Belo Horizonte: ANPAD, 2008.

VISCONTI, G. R. Arranjos cooperativos e o novo paradigma tecnoeconômico. Revista do BNDES, Rio de Janeiro, v. 8, n. 16, p. 317-344, dez. 2001.

WILLIAMSON, O. E. Comparative economic organization: the analysis of discrete structural alternatives. Administrative Science Quarterly, v. 36, p. 269-296, jun. 1991.

WILLIAMSON, O. E. The economic institutions of capitalism: firms markets, relational contracting. New York: New York Press, 1985.

ZYLBERSZTAJN, D. Papel dos contratos na coordenação agro-industrial: um olhar além dos mercados. Revista de Economia e Sociologia Rural, v. 43 n. 3, jul./set. 2005.

ZYLBERSZTAJN, D. Quatro estratégias fundamentais para cooperativas agrícolas. WORKING PAPER 02/017- FEA/USP, 2002. p. 1-21. Disponível em: $<$ http://www.ead.fea.usp.br/wpapers/>. Acesso em: 18 out. 2008. 